\title{
Protocolización sistémica de la actividad jurisdiccional ${ }^{1}$
}

\author{
Homero M. Bibiloni ${ }^{2}$ y Abelardo Servin ${ }^{3}$ \\ Universidad Nacional de La Plata - Argentina
}

Revista Derechos en Acción ISSN 2525-1678/ e-ISSN 2525-1686

Año 5/Nº 14, Verano 2019-2020 (21 diciembre a 20 marzo), 763-785

DOI: https://doi.org/10.24215/25251678e375

\section{Introducción. Un poco de historia}

La tardía puesta en marcha del fuero Contencioso Administrativo en la Provincia de Buenos Aires vio luz a partir de una acción judicial promovida por el Colegio de Abogados de la Provincia de Buenos Aires, que fue la culminación de otros amparos promovidos por jueces designados en el año 1999.

Cuestión que adicionalmente democratizaba y materializaba el acceso judicial efectivo en esta temática, al acercar la justicia al ciudadano, en lugar de llevarlo a la jurisdicción ubicada en la ciudad de La Plata, sede de la SCBA, lo que importaba en la práctica denegación de justicia.

El amparo en cuestión fue presentado ante la Suprema Corte de Justicia de la Provincia de Buenos Aires ${ }^{4}$ y resuelto por

\footnotetext{
1 El presente trabajo es parte de una línea de investigación desarrollada en el Centro de Investigación en Derecho Crítico de la Facultad de Ciencias Jurídicas y Sociales de la UNLP.

2 Abogado, profesor de Derecho Administrativo y de Derecho Ambiental de la UNLP y la UNAJ. Integrante del CIDERCRIT/UNLP.

3 Abogado, ex Juez del Fuero Contencioso Administrativo de la Provincia de Buenos Aires.

4 "Colegio de Abogados de la Provincia de Buenos Aires c/ Provincia de Buenos Aires s/ Amparo" Causa que tramitara por ante la SCJPBA Letra B- 64.474 Las reuniones entre funcionarios municipales y algunos especialistas se sucedieron y crearon un clima adverso a la puesta en marcha.
} 
ésta haciendo lugar a la pretensión, lo que puso fin al incumplimiento de preceptos constitucionales emanados de la carta magna provincial de 1994.

La originaria camada de jueces inició sus funciones en diciembre de 2003 y marzo de 2004.

Todo este proceso tuvo dilaciones, no sólo por la falta de celeridad judicial en instrumentar aspectos organizacionales que hacen a su cometido esencial, sino también por algunos resquemores políticos vinculados a un posible aumento de litigios, al estar el fuero más cerca de los ciudadanos y de los Municipios ${ }^{5}$

De esta escueta fragmentación histórica de la implementación del fuero provincial ha de destacarse esencialmente la circunstancia de que quién promoviera la acción fuera el Colegio de Abogados de la Provincia, el que se arropó de la legitimación representativa de los justiciables de la provincia.

Esta acción colectiva, acompañada y solicitada por aquéllos primeros jueces, se constituyó en un estandarte de la política judicial institucional provincial y de la plena vigencia del estado de derecho.

Como consecuencia de esta actividad en la jurisdicción, habrá de destacarse necesariamente que de hecho y de derecho, no puede descartarse de la gestión judicial a ninguno de sus actores.

La circunstancia de que el Colegio de Abogados Provincial se hiciera cargo de las inquietudes de los jueces designados y de los justiciables, revalorizó la actividad de los letrados y colocó a la Colegiación en un lugar esencial para la institucionalización provincial.

No es gratuito destacar, alguna extrañeza que provocó en los primeros instantes, en aquellas autoridades, la presencia de jueces designados en los despachos de sus Colegios. No obstante, en esa primera reunión, nació el germen que puso en acción la inquietud constitucional.

\footnotetext{
5 Las reuniones entre funcionarios municipales y algunos especialistas se sucedieron y crearon un clima adverso a la puesta en marcha del fuero.
} 
Se destaca esta situación, porque en la práctica, cuesta identificar a los letrados como auxiliares de justicia, como aquellos profesionales que trabajan con la justicia y no desde fuera de ésta.

Objetivamente, es cierto que los abogados del foro no están dentro de algún organigrama del Poder Judicial, pero sí están dentro de la justicia. Por lo que, los reclamos para una mejora en la justicia, no solo para los casos particulares de su incumbencia, sino para la gestión integral, también ha de ser una de sus responsabilidades primigenias.

La integración referida ha de recaer en la gestión CONCRETA Y DIARIA, de lo contrario, solo discutiríamos sobre el sexo de los ángeles.

\section{Problemas de la justicia}

Podríamos resumir nuestra mirada crítica de la justicia en general, todos sus fueros incluídos, conforme experiencias recíprocas, y por cierto absolutamente opinables, las siguientes: ${ }^{6}$

\subsection{Con relacion al sistema}

- Extrema lentitud.

- Burocracia excesiva.

- Inseguridad por distintas "normas" no escritas que se aplican en el Juzgado que nos toque, bajo la sola fundamentación del paradigma "Acá siempre se hizo así" o admitiendo una reformulación " es el criterio del juzgado"

- No se "resuelven" las causas. Se "dilatan" las causas, se "incrementan" las causas, se "complican" las causas, pero, no se resuelven las causas en la medida de su necesidad para el justiciable, destinatario final del servicio público de justicia.

6 Conforme Bibiloni Homero M., Servín Abelardo: "ACTUALIZACION DEL SERVICIO PUBLICO DE JUSTICIA PARA SUS ACTORES RESPETANDO SU SENTIDO ARTESANAL". Revista de la cultura jurídica de Italia y la Argentina IUSTITIA N 1 18-04-2018 IJ-XDII-767 
- Media un colapso del equilibrio de todo sistema: $\underline{\text { Acu- }}$ mulación creciente de la cantidad de causas que ingresan vs. $\underline{\text { Salida }}$ mediatizada por la cantidad de sentencias que se dictan.

\subsection{Con relacion a los jueces}

- Falta de liderazgo en la organización propia del juzgado y para el manejo de las causas.

- Ausencia en las audiencias.

- Alta delegación y consecuente ajenidad.

- El juez asume, si efectivamente lo hace, la causa al momento de dictar la sentencia.

- Los jueces están encerrados en sus despachos y no transitan por el juzgado y mucho menos por las Mesas de Entradas.

\subsection{Con relación a las sentencias}

- Como consecuencia de lo antedicho cuesta "armarlas" como una síntesis razonada de lo acontecido en el proceso, y con la precisa cita de las partes del expediente.

- Carecen de un método de causalización.

- Abundancia de generalidades no precisadas en las fojas de la causa que sorprende a las partes. ${ }^{7}$

\subsection{Con relación a los letrados:}

- Poca precisión en el formato de presentación, y alto nivel también de generalidades (V. gr. la "clara arbitrariedad de la contraria" que no se explica ni se funda).

- Manifestaciones jurídicas no causalizadas.

7 Cuando se leen las sentencias a veces parece que se dará la razón pero luego de una coma se dice no obstante\& y el resultado de tal discurso varía hacia lo opuesto, se produce una real magia pero jurídica. 
- Ausencia de sistematicidad en el relato de la demanda, se "va y viene" conceptualmente dentro de la misma

- Los hechos no tienen un estricto correlato probatorio.

- Problemas que se suscitan a los colegas por ausencia de conducción del proceso por parte del juzgado o la variabilidad según el interlocutor.

\subsection{Con relación a funcionarios y empleados judiciales.}

- Conflictos internos por ausencia de liderazgo.

- Conflictos con abogados, partes, terceros y peritos por la manera "personalizada" y "diferencial" como forma "natural" de resolver casos singulares.

- Falta de valoración concreta de la actividad de cada miembro del juzgado y la importancia de su tarea como parte dentro del todo.

En este marco de un orden que no es eficaz ni eficiente, el cual a veces funciona en una suerte de piloto automático, se plasma el "vale todo", lo que permite providencias tales como: "téngase presente" o lo que es peor y a los efectos de no resolver la cuestión "in límine", simplemente se opta por dar un traslado "en mérito a la presentación de fs. ... traslado a la contraria por ... días", el que muchas veces concluye resolviéndose con otra providencia del tipo: "Se resolverá oportunamente" sin indicación alguna de cuál es dicha "oportunidad", la que a veces ni siquiera ocurre, por perderse en el tiempo y en las fojas de la causa, o el aquilatado formalismo: "Ocurra por la vía que corresponda" sin la mínima referencia a cuál es la dicha vía ${ }^{8}$.

Los traslados previos a "resolver", cuestiones impertinentes, solo engrosan la cantidad de fojas del expediente judicial y dilatan indebidamente el proceso, postergando el análisis y la

8 Se supone que los jueces deberían ilustrar al respecto pero es más fácil derivar al espacio infinito. 
resolución de la cuestión en una procrastinación que se constituye en rutina.

Lo que agrava esta actividad es la excusa que se pontifica, vinculada a la garantía del principio de bilateralidad y defensa, cuando su resultado es, la violación a los principios de celeridad y, también, al proclamado de la defensa al aceptar lo inadmisible.

Parafraseando a Galileo Galilei en su "Eppur si muove" se puede concluir que el expediente a pesar del movimiento, sin embargo no se mueve. Se entra así en una dimensión demasiado conocida y repetida en nuestra gestión judicial, la del espejismo, en donde se aparenta un avance que Kafka bien define.?

\section{De lo micro a lo macro: paralelismo o integracion}

Así entonces, si pensamos en el formato mayor que es la justicia, vemos que dentro de ella están los códigos, los procesos, la dinámica de las partes, los contenidos, las secuencias temporales, lógicas; y si tales cuestiones las podemos llevar a mecanismos formales y básicos de actuación que funcionen pensados con criterios de eficacia y eficiencia en torno al proceso como un todo sintetizador, el sistema debería tender acumulativamente a una mejora en beneficio del conjunto.

Las Bases de Datos que sistematizan el seguimiento de las causas judiciales no tienen la finalidad de organizar los procesos de gestión de la actividad judicial, dado que se limitan a destacar los distintos pasos, las resoluciones y las presentaciones judiciales pero sin un análisis valorativo de dichas etapas. Lo mismo sucedía con el seguimiento manual.

Ambos modelos son un reflejo del simple "movimiento" de las causas. Lo consignamos así, expresamente en esta oportunidad, a los efectos de reflejar una situación por la cual se

9 Sillman Drake "Galileo at Work His Scientific Biography" Dover Phoenix Editions. Mineola, New York 1976 p. 357; Kafka Franks “El Proceso" 1a ed Buenos Aires: Colihue 2005 
interpreta usualmente que las mencionadas bases de datos constituyen en sí un sistema de gestión judicial, cuando siendo más rigurosos, lo que hacen es solo reflejar datos de las causas que se "mueven", tal lo antes indicado.

Lo propio sucede en un esquema fabril automotriz en donde no se puede confundir una base de datos donde se registran los procesos con un modelo productivo ${ }^{10}$.

Entonces, a pesar del avance tecnológico, descuidamos los procesos judiciales dentro de la gestión judicial como conjunto, con la peregrina idea de que ella se reduce tan sólo a una "base de datos". Se deja así huérfana a la justicia del gerenciamiento o administración (en términos públicos) de las causas dentro de dicha propia organización.

La libramos a su suerte, sin siquiera considerar la imperiosa necesidad de su tratamiento más profundamente.

El panorama que así se presenta, está reflejado en las palabras del Profesor Agustín Gordillo que repite en sus conferencias, charlas o fuera de los momentos expositivos en las jornadas ${ }^{11}$ que lo importante es que los jueces resuelvan sobre los temas que la ley les encomienda, y, agrega, lapidariamente, con una importante dosis de sentido común y practicidad: "sea de la forma que sea, mal o bien, pero que las causas se resuelvan..."

\section{EI ejemplo de la CSJN}

La propia Corte al dictar la acordada $4 / 07^{12}$ generó un formato y ordenamiento básico de utilidad para sí misma, en relación a los recursos extraordinario y de queja que le presentan las partes. Sólo se contaba con medidas de ordenamiento de las presentaciones procesales en la causa "Mendoza"13 a las que

\footnotetext{
10 Tomaremos la imagen de la industria automotriz como referencia ejemplificativa adecuada.

11 V. gr. Conferencia Honorable Cámara de Diputados de la Provincia de Buenos Aires 2015.

12 http://servicios.infoleg.gob.ar/infoleglnternet/anexos/125000-129999/126562/norma.htm

13 http://www.cij.gov.ar/riachuelo.html
} 
remitimos. Intentamos ampliar y razonar sobre esta perspectiva introduciendo el término "protocolos" para todos los actores del procesos, es decir también incluir a los peritos, demás protagonistas de la prueba y los mismos jueces. ${ }^{14}$

\section{Pinceladas sobre algunas realidades organizacionales}

Veamos estas características:

a) Principio de Unidad.- Anotamos que para la actividad jurisdiccional en la Provincia de Buenos Aires y en la gran mayoría de los organismos federales una de las características que se observa es la falta de UNIDAD en la conducción concreta de las causas. Decimos "concreta" puesto que en las formas, la unidad debe estar necesariamente en el Juez, conductor y líder procesal por imperio de la ley. ${ }^{15}$

Consecuentemente pueden darse en juzgados de un mismo fuero, a una puerta de distancia o aún dentro del mismo juzgado con más de una Secretaría, criterios disimiles para iguales situaciones, con igual norma aplicable ${ }^{16}$ sobre la base del paradigma cultural y organizacional inconmovible de cada juzgado ya aludido que dice "aquí siempre lo hacemos así", lo cual deviene en prácticas no cuestionadas aunque se las advierta disfuncionales total o parcialmente.

\footnotetext{
14 Eduardo Alfredo Borzi y Homero. M. Bibiloni, “Un punto de inflexión para el discurso jurídico: la acordada 4-2007 de la Corte Suprema de Justicia de la Nación", La Ley, 2008A-577.

15 Arts. 160, 18, 20 inc. 1 y 2 .24. 98.177, 178 ss. Y cc. De la Constitución Provincial; Arts. 3, 5, 6, 14, 34, 36, 37 ss y cc del Cód. Procesal de la Provincia de Buenos Aires; Arts. 5 inc. 2; 7 inc. 1 y 3; 10 inc. 2; 19 inc. 2; 22 inc. 2; 24 inc. 1; 26 inc. 3; 30 inc. 1, 2, 31 ss y cc del Código Procesal Contencioso Administrativo Provincia de Buenos Aires.

16 V.gr mecanismo de hacer los oficios, confronte de oficios a diligenciar por las partes, forma de conducir las audiencias, de pedir préstamo de expedientes, de los horarios para el desarrollo de las audiencias, diferentes criterios para la forma de exigir el pago de tasa de justicia, su contribución, aportes colegiales, distintos criterios para proveer las pruebas testimoniales. Distintas formas de interpretar la pertinencia de la absolución de posiciones de los funcionarios públicos en la medida que comprometan o no a la administración, etc.
} 
Paradigmas que se expresan entre otras formas, con conductas tales como:

- Asignar las causas a distintos miembros del organismo y una vez que son asignadas llevarlas una misma persona hasta su finalización.

- Establecer controles, si los hay, engorrosamente verticales, en tanto un mismo funcionario es quien debe controlar toda la actividad procesal previa a la firma del juez. Es el que "habilita" la firma. Firma que muchas veces es automática, sin lectura previa, habida cuenta del citado "control previo".

- Gestionar en compartimentos estancos, más allá de las normas procesales o exacerbándolas, con la excusa del volumen de causas. ${ }^{17}$

- Crear desde la génesis de nuestro sistema procesal, un mecanismo de "asignación de causas" que encubre una delegación, obviamente, no permitida por el legislador. El juez no puede delegar sus atribuciones en sus dependientes, en teoría. La práctica indica lo contrario.

b) Inseguridad.- Se crea una inseguridad técnica y jurídica por un modelo de delegación y falta de toda sistemática integral

En el sistema "AUGUSTA"18, por caso, que gestiona la base de datos de las causas, hay un campo reservado a quien "lleva el expediente" o en su espejo, la pregunta análoga de los letrados “...quiero hablar con el que despachó este proveído..."

En ambas situaciones, ha quedado institucionalizada la existencia de distintos empleados o funcionarios que conducen la causa, en contradicción con las funciones del responsable del organismo que es quien, en realidad, debe llevarlas.

\footnotetext{
17 V. gr. los que evitan tomar las audiencias, lo hacen empleados de rango menor " audiencistas" contrariando el art. 41 del Código Contencioso Administrativo de la Provincia de Buenos Aires y el espíritu de los artículos 34, 35 y 36 del Código Procesal Civil y Comercial de la Provincia de Buenos Aires.

18 Sistema determinado por la Suprema Corte de la Provincia de Buenos Aires para la gestión de base de datos de las causas
} 
En un imaginario benchmarking ${ }^{19} \mathrm{y}$, traspolando la actividad así llevada a cabo en la Justicia al ámbito de la fabricación de vehículos antes mencionado, nos encontraríamos con que cada operario lleva adelante la "fabricación de sus propios autos".

El resultado es predecible, tantos autos diferentes como "delegados" haya, lo cual es impensable en la unicidad de una automotriz donde todos son hechos de manera semejante al tener un patrón único de fabricación (en un juzgado serían los códigos aplicables).

Como la causalidad es propia del derecho, y los sistemas son secuencias concatenadas de acciones que deberán ser idénticas, encontramos a diferencia del ejemplo de la industria automotriz, que en lo judicial existe comparativamente, demoras inauditas, por las distintas formas de fabricar el mismo vehículo, e inexistencia de responsables formales concretos, lo cual es impensable en una línea de producción. Es decir que en lugar de un orden predecible obtenemos una alta dosis de incertidumbre caótica.

Como todo paradigma que se precie de tal, si nos preguntamos ¿en qué normas se fundamenta semejante actividad disfuncional? La respuesta es: EN NINGUNA.

Por el contrario, se las vulneran todas, sin siquiera adquirir conciencia de ello, por la consolidación de la práctica ritual ancestral del organismo que protege, entonces, a quien la utiliza de cualquier cuestionamiento que venga intra o extra sistema.

c) Oráculo.- Es necesario puntualizar que en la citada recurrente práctica se encuentra oculta otra norma no escrita que oficia de oráculo judicial: "Las complejidades de las causas impiden conducirlas sistémicamente" que se complementa con otra "La uniformidad en las resoluciones atenta contra la elaboración de criterios específicos" Dejando de lado así, ostensiblemente las normas procesales. So pretexto de las particularidades que existen en cada causa se vulneran los principios constitucionales y legislativos específicos.

19 Copiar procesos ajenos para mejorar los propios. 
Lo que se observa es que el tal "oráculo" es solo una excusa para la discrecionalidad. La sistematización la minimiza.

Queda así, como verdad revelada, que el juez no puede llevar un volumen determinado de causas y por esa razón, las causas son llevadas por los funcionarios y empleados del organismo. Lo que equivale a decir, que las causas NO SON LLEVADAS POR LOS JUECES. A confesión de parte...

En modo alguno puede considerarse que el examen previo por un determinado funcionario pueda suplir el necesario control del responsable del organismo. Dicha intervención previa no solo no suple el control del responsable, sino que en la práctica convierte al juez en un convidado de piedra. Un convidado ajeno al desarrollo del proceso.

d) Uniformidad.- Lejos de banalizarla, la actividad jurisdiccional la revaloriza porque la coloca en el marco normativo.

La sistematización de la actividad jurisdiccional se constituye en el único camino para actuar la legislación y la constitución.

Un juez, puede, por caso, conducir personalmente trescientos casos. En una realidad en que ese número puede ser llevado a más de treinta mil causas, la sistematización se impone.

Sistematización o caos es la disyuntiva. Todos los operadores judiciales saben en qué lugar de la disyuntiva se encuentra la justicia ahora.

\section{La protocolización como herramienta instrumental clave para un cambio de paradigma}

Ante este desorden operativo y organizacional, que con matices se repite a lo largo y ancho de nuestra judicatura, con excepciones por cierto, veamos esta idea que tratamos de transmitir en este artículo.

\subsection{Los protocolos en la vida comunitaria}

Los protocolos EN GENERAL son mecanismos que se utilizan en emergencias y en la vida de relación a efectos de tener 
certezas necesarias para avanzar en los procesos: PROTOCOLOS DE INCENDIOS, DE EMERGENCIAS, EN LOS AVIONES, EN LOS QUIROFANOS, ETC.

Pero repasemos el protocolo aéreo:

- Quien ha viajado dos veces en una misma aerolínea advierte que aunque el avión sea distinto, y el personal de a bordo también, el texto que reza la azafata y la demostración de la seguridad preventiva tanto a nivel auditivo como gestual, es igual. No varía ni es adaptado por cada tripulación.

- Quien haya visto en una película o viajado en avioneta, la partida de un avión permite advertir que hay una secuencia previamente establecida de lo que debe hacerse, cómo, cuándo y de qué manera. No hay creatividad ni improvisación alguna. Es una rutina predetermina0da porque se la ha elegido como la mejor entre opciones posibles.

- Ni hablar si durante el vuelo hay cualquier contingencia, también hay un manual de procedimientos: en suma OTRO PROTOCOLO. V. gr. si el aeropuerto de arribo está inoperable, qué se hace y cómo para desviar a otro alternativo.

\subsection{Concepto de protocolos para la justicia}

Hechas estas introducciones podríamos definir que un PROTOCOLO supone básicamente una unidad unívoca digital donde se consignan los DATOS RELEVANTES de la PRESENTACIÓN o de la RESOLUCIÓN. Datos que se constituirán, así, dentro de la PROTOCOLIZACIÓN SISTÉMICA PROCESAL, en el enlace vincular natural inter protocolos.

Protocolos diseñados y pensados en función de las directrices procesales, la bilateralidad procesal, y la articulación entre las partes, los peritos y el juez, en la actividad que se da durante el tiempo del proceso y sobre la base de la ingeniería procesal diseñada por los códigos que permiten operar las normas de fondo para cada fuero. Concluyendo, es una red vinculante entre las distintas etapas los actores y sus acciones dentro del proceso que se trate. 
Mediante esta propuesta se tiende a homogeneizar la actividad procesal:

- Inicialmente, en cómo formular las pretensiones.

- Ante la pretensión de una parte, la respuesta de la otra para que la espeje o rebata, conforme una lógica previa pero relacionada a la pretensión inicial.

- Ante la misma petición, mismo formato y misma respuesta.

- Impide volver hacia atrás por que las etapas se consuman objetiva y documentadamente.

- Esta conducta prediseñada da precisión.

- Al haber precisión, se le otorga certeza a todos los actores.

- Genera un efecto de acumulación por decantación de lo que será finalmente útil para cerrar el proceso, con la técnica del embudo o con la imagen de una pirámide invertida.

\subsection{Carácter vincular y secuencial. Los organizadores de los protocolos}

Estas herramientas hilvanan la actividad jurisdiccional de letrados y peritos, revalorizando los preceptos procesales y DANDOLES ANCLAJES OPERATIVOS A TRAVES DE TODO EL PROCESO, pero que por extensión también regulan la tarea judicial.

No son imperativos, sino indicativos ${ }^{20}$ y no cercenan la creatividad jurídica y la aptitud hermenéutica sino que simplemente la ordenan para que cuando ella surja - si lo hace - luzca debidamente.

\subsection{Valor de los protocolos}

- Favorecen la previsibilidad

20 En una primera etapa se los piensa como cargables en una página de los juzgados, como sugerencia del mismo para el mejor desarrollo de los procesos, sumando información a páginas que algunos juzgados poseen en nuestra Provincia. Ver punto 10 de este artículo 
- Disminuyen, por lo tanto, la discrecionalidad a expresiones deseablemente mínimas

- Impiden la arbitrariedad.

- Ponen en valor las normas procesales

- Materializan las normas éticas evitando conductas abusivas, dilatorias, etc.

- Ordenan las vinculaciones procesales

- Descartan los ruidos sistémicos que corroen con el atraso y la confusión estos procesos, sea por imprecisión, o por mala fe.

- Facilitan la fundamentación de providencias y presentaciones

- Permiten descartar escritos y resoluciones inoficiosas.

\subsection{Los protocolos, la digitalización y la oportunidad}

LOS PROTOCOLOS realimentan y estructuran las bases de datos $^{21}$ de la gestión de causas físicas o digitalizadas, a fin de que esas bases no sean solo enumeración y volcado automático y ordenado de presentaciones, resoluciones y pases sino que se constituyan en un sistema integral de organización de la gestión judicial. ${ }^{22}$

21 Debe considerarse la base de datos de las causas digitalizadas, con sus correspondientes pasos, peticiones y resoluciones, ordenando los registros que secuencialmente se van agregando, los denominados "input", pero lo cierto es que no distinguen, ni analizan ni desagregan sus contenidos, con lo cual en sí mismas son insuficientes.

Tenemos, entonces, que las presentaciones y resoluciones se ordenan secuencialmente, exclusivamente según parámetros temporales.

Por caso esquemáticamente: DEMANDA, TRASLADO, CONTESTACION, APERTURA A PRUEBA, PRUEBA, ALEGATOS, SENTENCIA, APELACIÓN, AGRAVIOS, CONTESTACION Y ELEVACION, EJECUCION FINAL DE LA SENTENCIA. En donde se registran y reproducen presentaciones de las partes y resoluciones judiciales.

22 Se pretende que la misma resulte un sistema de gestión judicial completa que para ser tal, habrá de agregar y relacionar los registros internos de esas presentaciones y resoluciones de tal forma de constituir una base de datos relacional e integral que contemple no sólo las vinculaciones registrales y sistémicas de cada una de las presentaciones internamente sino también su relación con las demás.

Se aprovechan así los datos previamente cargados para sus usos posteriores, se eliminan las repeticiones innecesarias, se evitan errores de copiado o de transcripciones, se gana 
Así, debemos aprovechar la oportunidad que nos da la digitalización de las causas judiciales, porque si no se les asigna un criterio estratégico e inteligente seguirán los atrasos y los conflictos a los que nos tienen acostumbrado los procesos judiciales.

Los mismos inconvenientes que tenemos en la justicia con causas en soporte físico, los tendremos en soporte digital de no tomar una solución integradora.

\subsection{Los sistemas de calidad}

Cabe señalar también que habrá que tomar con precaución la incorporación de las certificaciones ISO a la gestión judicial, en tanto en éstas se contemplan los procesos y no su diseño o finalidad. La cuestión teleológica está ausente en las normas ISO u otros sistemas de calidad.

\section{Nuestra propuesta}

\subsection{Conceptualización}

Así es que se proponen los PROTOCOLOS como instrumentos que reúnen, entre los valores antes indicados dos características esenciales:

- La primera, vinculada al buen orden de la presentación o la resolución: partes, pruebas, pretensiones, fundamentación, peticiones, donde claramente figuren las partes, la pretensión, las distintas pruebas desarrolladas en distintos acápites, las peticiones procesales: demanda, contestación, prueba, peticiones varias, alegatos, pedido de sentencia, apelación y agravios en primera instancia, como así también en la sentencia y en su ejecución.

- La segunda característica, se refiere a la vinculación de las distintas presentaciones y cada uno de los elementos de éstas, con la de las partes y a su vez entre dichas partes.

tiempo, se evitan los "agujeros negros" de la práctica jurisdiccional, las normas procesales son así eficientes. 
La falta de ordenación precisa de la actividad jurisdiccional, impide generar cualquier sistema, y si ello sucede, la justicia se constituye en un esqueleto, en un marco, desprovisto de todo contenido.

El proceso judicial se parecerá, de tal guisa, a un río tormentoso formado por violentas precipitaciones, que corre desordenadamente, arrastrando cuantos elementos materiales encuentre en su camino hasta detener su marcha, dejando los acúmulos orgánicos e inorgánicos en un lecho desordenado que dará cuenta de la tormenta y del que poco se podrá extraer que pueda beneficiar a los justiciables.

El esquema puesto a consideración se asimila a las vías de un tren, lineales, ordenadas, con un trayecto previsible que facilite la llegada a la terminal (sentencia), en un tiempo razonable.

\subsection{La tutela judicial efectiva}

El mandato constitucional bonaerense del artículo $15^{23}$, encontrará así, un camino práctico y concreto para viabilizase. El proceso será previsible. El rigor en el tratamiento de los datos de la causa dará lugar al mejoramiento sustantivo de los mecanismos para su plena vigencia y serán fácilmente percibidos por los operadores del servicio público de justicia repercutiendo en el entramado de la población, minimizando las preocupaciones, hacia una verdadera pacificación social.

\section{El contencioso provincial}

Si analizamos el proceso contencioso administrativo en la Provincia de Buenos Aires contenido en la ley 12.008, la aplicación supletoria del art. 77 mediante, del CPCC y sus

\footnotetext{
23 ...."Artículo 15.- La Provincia asegura la tutela judicial continua y efectiva, el acceso irrestricto a la justicia, la gratuidad de los trámites y la asistencia letrada a quienes carezcan de recursos suficientes y la inviolabilidad de la defensa de la persona y de los derechos en todo procedimiento administrativo o judicial.
} 
modificaciones podemos extraer esquemáticamente cuatro etapas secuenciales:

1.- Inicial: Demanda (art. 27 CCA); Traslado (art.32 CCA); contestación (art. 37 CCA); Excepciones (arts. 34, 35 y 36 CCA); Traslado (art.34 inc. 3 CCA); Contestación (art.34 Inc. 3 CCA); Resolución de las Excepciones (art.36 CCA). ${ }^{24}$

Cuestiones de Competencia (arts. 5, 6, 7 y 8 CCA); Intervención de Terceros (art. 11 CCA, arts. 90 y ss CPCC); Admisibilidad (art. 14 y 31 CCA); Pago Previo (art. 19 CCA); Medidas Cautelares (art. 22, 23, 24, 25 y 26 CCA); Presentación de Nuevos Documentos y Remisión de Expedientes Administrativos (art. 30 CCA); ampliación o transformación de la demanda (art. 32 CCA); Reconvención (art. 39 CCA); Agregación de Nuevos Documentos (art. 40 CCA).

2. Intermedia: Prueba (art. 41 CCA, arts. 358 y ss CPCC); Pertinencia (art.41 CCA); Producción (art. 41 CCA); Hechos Nuevos (art. 42 CCA); Medidas para Mejor Proveer (art. 46 CCA).

3. Final: Alegatos (art. $48 \mathrm{CCA}$ ); y Sentencia (arts. 49 y ss CCA); Recursos (art. 52 y ss CCA) y los Otros Modos de Terminar el proceso: Desistimiento, Allanamiento, Transacción, Conciliación, Caducidad de Instancia (arts. 61 y 62 CCA; arts. 304 a 318 CPCC).

4. Posterior: Ejecución de la sentencia (art.63 CCA).

Estas etapas están limitadas y separadas procesalmente por el principio de preclusión.

De tal forma que una vez atravesada la barrera que las separa, no se puede volver a la anterior.

La idea de protocolización de la actividad jurisdiccional se afinca en la necesidad de relacionar:

a) Las distintas partes de cada presentación;

b) Las presentaciones entre sí;

24 CCA: Código Contencioso Administrativo de la Provincia de Buenos Aires. (ley 12008 y modificatorias) 
c) Las presentaciones con las resoluciones

d) Las etapas procesales

Para así, armonizar todas las variables procesales sin que se generen conflictos entre ellas, quedando así, cada etapa comprendida en la posterior a modo de MAMUSHKAS. ${ }^{25}$

Así, los datos, que por ejemplo, se vuelcan en la demanda con relación al módulo "PRUEBA" (testigos, informativa, reconocimiento judicial, confesional) habrán de tener una correspondencia con los principios procesales de pertinencia y procedencia. De forma que, desde el inicio del proceso estén claramente demarcados:

- El sumario de la acción deducida como resumen general.

- las pretensiones debidamente caracterizadas.

- los hechos debidamente desagregados e identificables,

- Cada prueba relacionada a cada hecho

- El derecho relacionado a los hechos.

- La petición relacionada con los hechos y con el derecho.

La producción de la prueba en los procesos ordinarios, al no filtrarse la impertinente, se eterniza innecesariamente. Lo que ocasiona ruidos sistémicos que se traducen en un atraso patológico y en un desorden generalizado.

Un atraso por todo el tiempo que lleva producir una prueba innecesaria que no será tenida en cuenta al sentenciar y un desorden porque, para producir esta prueba, se distraen personal y recursos, incorporándose a la causa fojas inútiles y enorme dispendio "energético" del sistema.

\section{Ejemplos de protocolos}

Deberían existir los siguientes básicamente:

- Escritos de los letrados

- Providencias Judiciales

25 Muñecas rusas que encastran unas con otras de menor a mayor 
- Relaciones testimoniales con datos fácticos.

- Idem de los elementos documentales.

- Idem de los Informes Periciales

- Idem de la prueba de Informes

- Idem de las inspecciones Oculares

- Oficios

- Cédulas

- Sentencia

- Etc.

Los protocolos condensarán y organizarán la actividad, en tanto que cada uno de ellos, estará sistematizado internamente y vinculado a su vez con los restantes.

En la última parte de este trabajo se agrega un diagrama de la actividad protocolar y ejemplos esquemáticos de protocolos propiamente dichos (Anexos $1^{26}, 2^{27}$ )

Podrán observar los actores de los procesos judiciales (Funcionarios y empleados del Poder Judicial y Letrados) la simplicidad que trasuntan los protocolos y el cursograma. Esta práctica servirá, como facilitadora del real acceso debido a la justicia, tal la manda del Art. 15 de la Constitución de la Provincia de Buenos Aires, operada de manera puntual y concreta.

\section{Instalación de protocolos}

Varios juzgados a nivel provincial y nacional han habilitado páginas web, por medio de las cuales se comunican con los usuarios, brindando informes y desarrollando esquemas de oficios y escritos varios, para facilitar la tarea de letrados.

Se destacan en este trabajo las páginas correspondientes a los juzgados $\mathrm{N}^{\circ} 8$ de Quilmes a cargo de la Doctora Claudia

\footnotetext{
${ }^{26}$ En este anexo: Un diagrama de la protocolización de la prueba correspondiente a las Etapas INICIAL, INTERMEDIA Y FINAL

27 En este anexo: Un ejemplo de SUB PROTOCOLO DE PRUEBA dentro de un PROTOCOLO DE DEMANDA.
} 
Celerier (http://juzciv8quilmes.com.ar) y al Juzgado $\mathrm{N}^{\circ} 2$ de Familia del mismo Departamento Judicial a cargo del Doctor Pablo Ferrari (http://juzgadofamilia2ql.com.ar) con quienes llevamos a cabo un taller conjunto en el Colegio de Abogados de Quilmes recientemente. ${ }^{28}$

El concepto, entonces, de protocolización de la actividad jurisdiccional está vinculado a esas experiencias que van surgiendo en algunos organismos. Simplemente se agrega la sistematización de los protocolos, relacionándolos de la forma descripta anteriormente.

\section{Conduccion y resultados}

\subsection{El liderazgo}

Al frente de la protocolización debe estar el responsable del organismo, es decir el Juez y no el "funcionario delegado".

No cabrían así, excusas relacionadas a la cantidad de causas que se deben llevar en un organismo a cargo del mismo juez, puesto que no se analizarían uno a uno los miles de expedientes sino solamente su sistematización protocolar, su proyección, los procesos de manera macro, y los datos riquísimos que surgirán de los filtros aplicables a los protocolos. Es decir con una técnica pertinente, reducir la complejidad.

\subsection{Ordenamiento sistemico}

Dentro de los procesos contencioso administrativos, los civiles, comerciales y los laborales y aún los penales, cada uno con sus matices, se reconocen distintas etapas troncales (Las incidencias, a los efectos de la protocolización serán consideradas como etapas con relativa autonomía) 1.-Demanda y Contestación: Traba de la Litis; 2.-Prueba; 3.-Sentencia; 4.-Ejecución de la Sentencia para situaciones imprevistas existirán "protocolos base" multiuso.

\footnotetext{
28 "Nuevas Herramientas para Mejorar el Servicio de Justicia“" Colegio de Abogados de Quilmes 15 y 22 de Mayo de 2018
} 
Dentro de las particularidades de esta propuesta se remarca el acento que se le asigna a la PRUEBA en el marco del Contencioso ${ }^{29}$, lo que va desde la protocolización de la apertura a prueba (art. $41 \mathrm{CCA})^{30}$, a las distintas particularidades que se puedan originar en lo que hace a la pertinencia y al desarrollo de un HECHO NUEVO, como al resto de las acreditaciones ofrecidas.

También a la CERTIFICACION DE LA PRUEBA, que así se constituirá en una decantación natural de las anteriores, facilitándose la claridad del desarrollo probatorio.

La secuencialidad se puede visualizar como una escalera completa y armónica. Los escalones que la integran tienen la altura idónea y amigable para que nadie "tropiece" en su tránsito.

Es decir, que los protocolos, finalmente, son funcionales al modelo de integración y acumulación. No poseen contradicciones, es decir, no le faltan "escalones".

Su ventaja reside en la posibilidad de comprender unos en otros, los que así vinculados, ordenan el proceso impidiendo la dispersión sin vedar las ricas alternativas creativas de contenido que puede tener la variabilidad procesal. Al ordenarse cada uno se integra y queda comprendida en la otra etapa o fase.

\section{Conclusiones}

La protocolización sistémica de la actividad jurisdiccional facilitará la tarea, trazando un hilo conductor sin necesidad de incorporar controles aislados inorgánicamente, tales como los que se solían ver en las solapas de expedientes judiciales en manuscrito con distintas letras, o en extraños subrayados en birome no incluidos por las partes, de ciertas partes de las presentaciones, o textos en lápiz (quizás estos con la pretensión de ser borrados luego, aunque muchas veces finalmente quedaban).

29 Ver los anexos.

30 CCA Código Contencioso Administrativo de la Provincia de Buenos Aires. 
Esta es la oportunidad que se nos brinda a los agentes y actores procesales, ante la digitalización de los expedientes judiciales, para que no haya solapa donde colocar "su" guía de trámite o "sus" observaciones.

Eliminadas esas conductas asistémicas gracias a la desaparición del expediente físico habremos de implementar un modelo en donde se incorporen esas inquietudes dentro mismo de la organización digital.

La protocolización auxiliará a quien consulte un expediente judicial, sea físico (hasta su desaparición total) o digital para un rápido control de presentaciones y resoluciones judiciales.

La ventaja de la protocolización, es que en sí misma, no implica ninguna reforma procesal, por el contrario, la protocolización es un facilitador del cumplimiento de normas procesales que han sido descuidadas por desuetudo.

Por lo demás nuestra propuesta:

- Es versátil puesto que, naturalmente habrá de acomodarse a futuras reformas procesales.

- Permite preparar los antecedentes y mejorar la estructura de la formulación de la sentencia.

- Incorpora a los escritos y resoluciones judiciales una guía conceptual que se anidará a las precedentes y a las por venir, a modo del "Kanban" (Sistema de tarjetas recreadas por el Toyotismo). ${ }^{31}$

Esta integración surge como un proceso natural y moderno de gestión por el que se rediseña la nueva organización, incorporando conceptos de la Reingeniería. (Michael Hammer y James Champy (1993- 1995) ${ }^{32}$

31 Shingó.Shigeo (1989) A Study of The Toyota Production System from an Industrial Engineering Viewpoint.Productivity Press. P. 228)

32 Ospina Duque, Rodrigo, LA REINGENIERÍA DE PROCESOS: UNA HERRAMIENTA GERENCIAL PARA LA INNOVACIÓN Y MEJORA DE LA CALIDAD EN LAS ORGANIZACIONES. Cuadernos Latinoamericanos de Administración [en línea] 2006, II (Enero-Junio): [Fecha de consulta: 15 
El desafío, entonces, está enraizado en la incorporación definitiva de conceptos holísticos mediante los cuales se habrán de amalgamar las nuevas tecnologías digitales con los nuevos sistemas de gestión judicial y el cambio de cultura para jueces y abogados.

En suma, la propuesta supone utilizar las técnicas de uso corriente en la sociedad moderna, ayudados por la informática, para actualizar y mejorar sin necesidad de modificaciones legislativas, los procesos judiciales.

Ciertamente es indicativa para las partes, para el juez, y puede ser utilizada por uno o muchos jueces, pero a poco que todos vean la simplificación que supone, entendemos que su uso irá en aumento, sin contar que dicho prediseño, permite múltiples usos posteriores por filtros diversos para obtener información crítica, sacar estadísticas y tomar decisiones con bases cuali-cuantitativas fundadas. En fin, llevar de la mano a los usuarios por un camino SIMPLE, y al AUTO CONTROL de la actividad procesal judicial en la cual están inmersos.

Por último, la Constitución, las leyes y la jurisprudencia por más que las recitemos y copiemos de memoria, de no tomar un camino que las concrete en la práctica, se pulverizarán cuando bajen de ese cielo de los conceptos puros a la tierra de los justiciables. ${ }^{33}$

de febrero de 2018] Disponible en: <http://www.redalyc.org/articulo.oa?id=409634344006> ISSN 1900-5016 p. 96

33 Ihering Rodolfo fue quien acuñó la frase "El Cielo de los Conceptos Puros" y el drama que implica una praxis terrenal que nada tiene que ver con aquéllos conceptos: (“Jurisprudencia en Broma y en Serio" Traducción de Román Riaza. Editorial Revista de Derecho Privado. Madrid 1983) 